\title{
Effects of Cannabinoids on Sleep and their Therapeutic Potential for Sleep Disorders
}

\author{
Malvika Kaul $^{1} \cdot$ Phyllis C. Zee ${ }^{2} \cdot$ Ashima S. Sahni $^{1}$ (D) \\ Accepted: 14 January 2021 / Published online: 12 February 2021 \\ (C) The American Society for Experimental NeuroTherapeutics, Inc. 2021
}

\begin{abstract}
The recent trend for legalization of medicinal cannabis and cannabinoid-containing products, together with their soporific effects, has led to a surge of interest of their potential therapeutic role in the management of some common sleep disorders, such as insomnia, sleep disordered breathing, and restless legs syndrome, and less common disorders such as narcolepsy and parasomnias. Although much of the pre-clinical and clinical data were derived from studies with relatively small sample sizes and limited by biases in assessment, and in clinical trials lack of allocation concealment, as a whole, the results indicate a potential therapeutic role for cannabinoids in the management of some sleep disorders. Clinical trials are underway for insomnia and obstructive sleep apnea management, but there remains a substantial need for rigorous large multi-center studies to assess the dose, efficacy, and safety of the various types of cannabinoids on sleep disorders. This review aims to summarize the modulatory effects of cannabinoids on sleep physiology and provide a critical evaluation of the research on their potential therapeutic benefit in various sleep disorders.
\end{abstract}

Key Words Cannabinoids $\cdot$ Sleep $\cdot$ Hypnogram $\cdot$ Sleep apnea $\cdot$ Sleep disordered breathing $\cdot$ Insomnia $\cdot$ Marijuana $\cdot$ Cannabis $\cdot$ Restless leg syndrome $\cdot$ Nightmares $\cdot$ Narcolepsy $\cdot$ Parasomnia

\section{Introduction}

Cannabinoids are psychoactive compounds found in the cannabis plant. With legalization, they have become the most frequently used psychoactive substance in the world. Around 104 cannabinoids have been identified, out of which delta-tetra-hydrocannabinol (THC) and cannabidiol (CBD) have been most widely studied [1]. Due to their psychotropic effects and somnolence, they have been frequently used for sleep induction and in conditions like post-traumatic stress disorder (PTSD)-related nightmares. We aim to provide a comprehensive review of the literature on effects on these

Ashima S. Sahni

asahni@uic.edu

1 Division of Pulmonary, Critical Care, Sleep and Allergy, Department of Medicine, University of Illinois at Chicago, 909 S Wolcott Ave, Room 3135 (MC 719), Chicago, IL 60612, USA

2 Department of Neurology, Center for Circadian and Sleep Medicine, Northwestern University Feinberg School of Medicine, 305 E. Chicago Ave., Chicago, IL 60611, USA cannabinoids on normal sleep architecture as well as various sleep disorders. Historical Significance of Cannabinoids

Marijuana, or cannabis, is recognized as a schedule I drug by the US Drug Enforcement Agency (DEA) with high potential for abuse. An exception to this is the cannabis-derived compound dronabinol which is classified as schedule III [2]. Marijuana is also one of the most widely cultivated drugs worldwide [3]. Historically, it may have been first utilized in the third millennium B.C. based on archeological evidence; however, the first evidence of its medicinal use is from around $400 \mathrm{AD}$ [4]. In the USA, it is legalized for medicinal use in 33 states, four permanently inhabited territories, and the District of Columbia. Recreational use is legalized in 11 states, District of Columbia, Northern Mariana Islands, and Guam [5, 6].

There is growing data on the use of these compounds for medicinal purposes, such as treatment of pain and chemotherapy-related side effects. In addition, there has been a surge of interest of their use in other conditions [7]. Directly relevant to this review is their potential general sleeppromoting effects and effects on specific aspects of sleep physiology, which may be advantageous in the treatment of some sleep disorders. 


\section{Sleep Physiology}

Sleep is an essential physiologic function that alternates with wakefulness. The structural organization of normal sleep is broadly organized into two alternating phases: non-rapid eye movement (NREM) and rapid eye movement (REM) Fig. 1a (normal sleep hypnogram).

The regulation of the sleep-wake cycle is a complex interplay between various neuroanatomical and neurochemical systems. REM sleep is regulated by neurons present in the pons and hypothalamus and NREM sleep is regulated by neurons in the preoptic areas (like the ventrolateral preoptic nucleus) that inhibit the ascending arousal systems [8]. These sleep-promoting regions are primarily regulated by inhibitory neurotransmitters like gamma-aminobutyric acid (GABA) or galanin. REM sleep is also promoted and maintained by cholinergic neurons located in the dorsolateral pons [9].

Wakefulness is mediated primarily by neurons in the reticular formation, especially the rostral half. These neurons send excitatory projections to areas of the thalamus, hypothalamus, and forebrain. Cholinergic, monoaminergic, and the orexin/ hypocretin neurotransmitters are primarily involved in promotion of wakefulness $[8,10]$.

Along with changes in neuronal activity, there are dynamic fluctuations in physiology during sleep that involve the cardiovascular, autonomic, respiratory, and endocrine systems. Respiratory patterns vary during sleep with a regular respiratory pattern in NREM sleep and a more irregular pattern in REM sleep. The central and peripheral chemo- and mechanoreceptors respond to changes in oxygenation and ventilation, but this response also varies between sleep and wakefulness, becoming more pronounced during REM sleep. Sleep also decreases the tone of the pharyngeal muscles, which can be further exacerbated by certain positional changes. Further, there is reduction in the tone of other upper airway and intercostal muscles which leads to increased upper airway resistance, decreased thoracic movements, and ultimately hypoventilation which becomes especially pronounced during REM sleep [11]. This ventilatory load is normally counteracted by compensatory mechanisms in the awake state but is delayed during sleep [12]. This load compensation can be further pathologically reduced in conditions like obstructive sleep apnea (OSA) [13].

\section{Endocannabinoid System}

The endocannabinoid system is primarily comprised of endogenous lipid ligands and cannabinoid receptors. Endogenous ligands include 2-arachidonoyl glycerol (2-AG), eicosanoids,

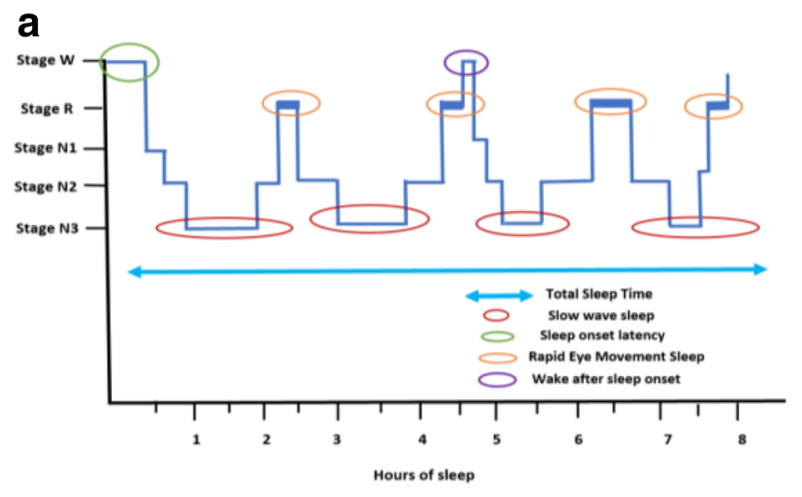

Normal Sleep hypnogram

C

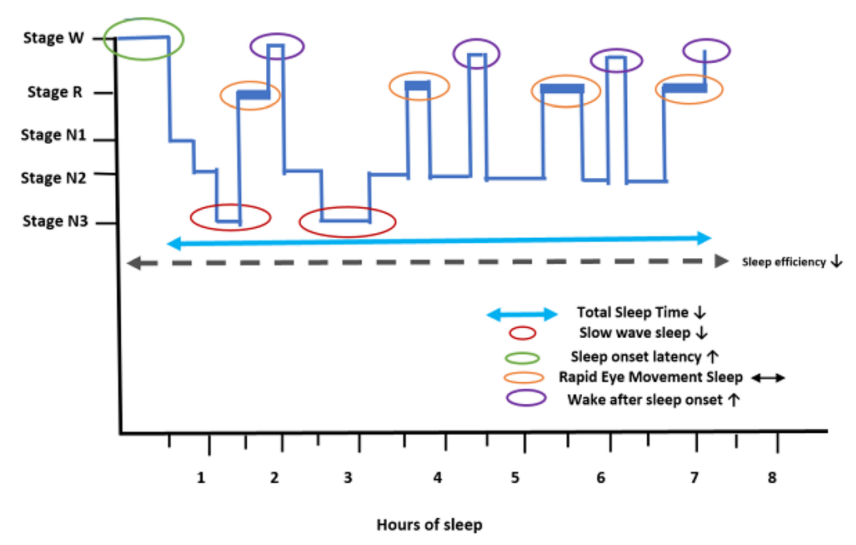

Long-term effects of cannabis on sleep architecture

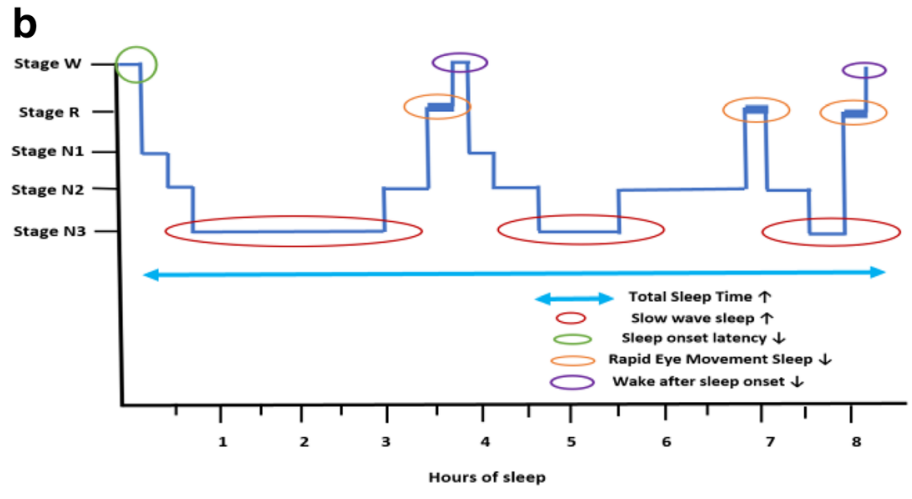

Short-term effects of cannabis on sleep architecture

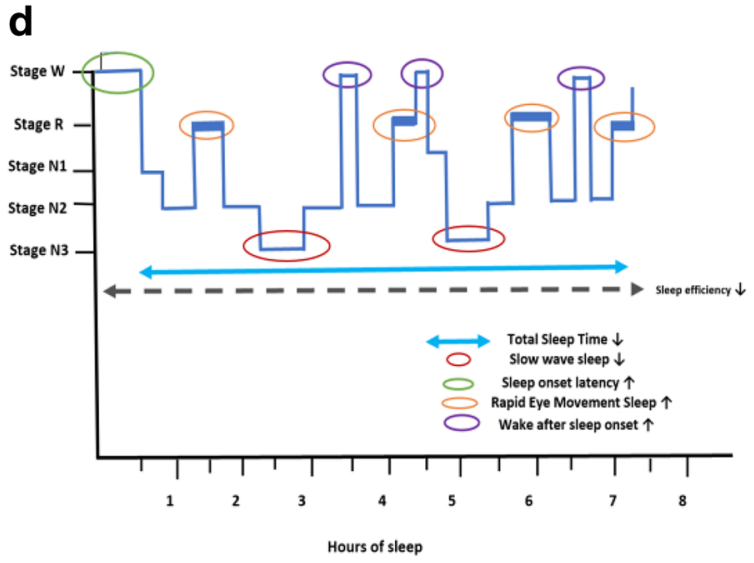

Effects of cannabis withdrawal on sleep architecture

Fig. 1 Summary of effect of cannabis and THC on sleep architecture (short term, long term and effects of withdrawal of cannabis) [100] 
and anandamide (N-arachidonoylethanolamide) [14]. These (as well as exogenous compounds) act on two types of cannabinoid receptors: $\mathrm{CB} 1$ and $\mathrm{CB} 2$. $\mathrm{CB} 1$ receptors are primarily central (and present in the thalamus, hypothalamus, cortex, hippocampi, limbic system, and basal ganglia) whereas CB2 are predominantly peripheral (in the immune system, lung, and liver) with the exception of those found in the brainstem [15-18].

It is suggested that $\mathrm{CB} 1$ receptors located in the pons and basal forebrain may be involved in sleep induction [19]. This process is possibly related to activation of cholinergic neurons located in the basal forebrain and pons via CB1 receptors, assisting in the induction of sleep [19]. The serotonergic transmitter system located in dorsal raphe nucleus of the brainstem is also involved in modulation of the sleep-wake cycle [20]. These serotonergic neurons receive afferent inputs from arousal systems including orexin/hypocretin, histamine, and noradrenaline systems [21]. Some studies have also suggested the role of the endocannabinoid system in modulation of the serotonin system [22, 23]. CB1 receptors have been shown to enhance the activation of the serotonergic system yielding a potential regulatory role in the sleep-wake cycle [24, 25].

The two widely studied exogenous cannabinoids THC and $\mathrm{CBD}$ have different actions on the $\mathrm{CB} 1$ and $\mathrm{CB} 2$ receptors and thus different degrees of psychoactive effects (Table 1 compares the mechanism and effects of these two compounds).

THC predominantly acts on the CB1 receptors. Its various effects may differ depending on the dose, with low doses having a sedative effect, moderate doses having a stimulant effect, large dose having a hallucinogenic effect, and very large doses having a psychotic effect. Due to these dosedependent effects, abuse potential is increased [26-28].

$\mathrm{CBD}$ on the other hand is a noncompetitive antagonist of CB1 receptors, with somewhat counter effects of THC, thus reducing the potency of THC. It has medicinal properties and can be used as an analgesic, anti-inflammatory, anti-depressant, and anxiolytic [27].

\section{Cannabinoids and Sleep Architecture}

The effects of these compounds on various stages of sleep with different modes of administration including inhalational or oral use have been evaluated in some small studies revealing variable effects on sleep stages. Most of the studies examining these effects were polysomnography-based primarily done in the early 1970s. These studies included several animal and small human studies. Most of these studies evaluated the effect of THC and cannabis; thus, data on effects of CBD are lacking [29].

\section{Effects of Cannabis and THC on Sleep Architecture}

1. Acute exposure/short-term use: With short-term use, it is suggested that there is more sleep consolidation, reduced sleep onset latency (SOL), increased total sleep time, and decreased wake after sleep onset (WASO). Acute administration of THC has also been associated with decreased REM sleep and increased slow wave sleep (SWS), similar to some animal studies [30,31]. However, the effects on slow wave sleep and total sleep time are not persistent (Fig. 1b).

2. Long-term use: In contrast to the above, chronic administration of THC has been shown to decrease SWS, suggesting the possibility of tolerance with its long-term use. Effects of the chronic use of THC on REM stage are nonuniform, unlike SWS effects seen in various human and animal studies [32-34]. There is also suggestion of increased sleep disruption due to increased SOL, increased WASO, and reduced TST [35]. A polysomnographybased study demonstrated these effects by evaluating objective and subjective measures of sleep in current cannabis users. The majority of participants showed decreased overall sleep time (78\%), with increased SOL ( $>30 \mathrm{~min}$ ), poor sleep efficiency $(<85 \%)$, and increased WASO (54.7). Increased REM sleep latency (average

Table 1 Comparison between cannabidiol (CBD) and tetrahydrocannabinol (THC)

\begin{tabular}{|c|c|c|}
\hline & Cannabidiol (CBD) & Tetrahydrocannabinol (THC) \\
\hline Mechanism & $\begin{array}{l}\text { Inverse agonist for } \mathrm{CB} 2 \text {, non-competitive antagonist } \\
\text { to } \mathrm{CB} 1,5 \mathrm{HT} 1 \mathrm{a} \text { agonist }\end{array}$ & Higher affinity to $\mathrm{CB} 1$ \\
\hline Effect & $\begin{array}{l}\text { No psychoactive component, potential analgesia, } \\
\text { anti-inflammatory, anti-depressant, and anxiolytic } \\
\text { effect }\end{array}$ & $\begin{array}{l}\text { Psychoactive component with sedative effect at small doses, stimulant } \\
\text { effect at moderate doses and hallucinogenic/psychotic effects at larger } \\
\text { doses. }\end{array}$ \\
\hline $\begin{array}{l}\text { Sleep related effects } \\
\quad \text { (acute exposure) }\end{array}$ & $\begin{array}{l}\text { - Studies are lacking. } \\
\text { - Overall has alerting properties especially in } \\
\text { combination with THC. } \\
\text { - Associated with improved sleep based on } \\
\text { subjective assessment. (30) }\end{array}$ & $\begin{array}{l}\text { - Decreases SOL } \\
\text { - Increases SWS (contrary results have also been reported) } \\
\text { - Decreases REM sleep and REM density }\end{array}$ \\
\hline Dependence & Less dependence & Greater misuse potential and greater risk of withdrawal \\
\hline
\end{tabular}


$114.5 \mathrm{~min}$ ) as well as decreased percentage of REM sleep $(17.7 \%)$ were also noted (Fig. 1c).

3. Withdrawal effects: With cannabis withdrawal, there are associated sleep disturbances and vivid dreams. A study comparing different PSG characteristics in prior heavy marijuana users demonstrated lower total sleep time (TST), decreased SWS and decreased REM latency as compared to controls (Fig. 1d). This group also had longer sleep onset and worse sleep efficiency than the control group, though the study was limited by lack of baseline PSG data in both groups [36]. Another study also showed an increase in periodic limb movements (PLMs) after abrupt cessation of heavy marijuana use [37-39]. Withdrawal-related sleep disturbances have been found to be worse among heavy users and usually occur in about 24-72 $\mathrm{h}$ after discontinuation and can persist up to 67 weeks. Given these duration-dependent variable effects on sleep architecture, the role of cannabinoids in sleep disorders remains under investigation.

\section{Effect of CBD on Sleep Architecture}

Data regarding effects of cannabidiol or CBD on sleep are limited. Studies in rats injected with increasing dosages of CBD showed an increase in total percentage of sleep, with a decrease in REM latency at lower doses and an increase in REM latency at higher doses [40, 41]. At this time, there are a lack of human studies collaborating these findings. A recent controlled trial did show increased sleepiness based on subjective assessment in subjects who used CBDdominant cannabis, but it is unclear if this was due to the small amount of THC in it [42]. Chronic effects of CBD are yet to be studied. Thus, studies on the isolated effects of CBD on sleep architecture are limited and mostly have mixed results.

\section{Effects of Combined THC and CBD on Sleep Architecture}

Studies of CBD in combination with THC have shown that CBD has more alerting effects and tends to counteract the sedative effects of THC especially at higher doses, as shown in a double-blinded, placebo-controlled four-armed crossover study using EEG monitoring [28].

In summary, most of these studies evaluating effects of cannabis and cannabinoids are limited by differences in study designs, sample sizes, and procedures, as well as the ratios of THC to CBD used. These effects are summarized in Fig. 1 with various hypothetical hypnograms depicting effect of cannabinoids on stages of sleep.
Endocannabinoids and Sleep-Wake Cycle

The endocannabinoid system (ECS) incorporates a complex interplay involved in regulation of various physiologic functions. The system's potential role in the regulation of the circadian rhythm has been linked to its effect on the suprachiasmatic nuclei via the CB1 receptor-related GABAergic effect $[43,44]$. Studies in rodents have shown lower levels of endocannabinoids during the "light phase" but increased levels during the "dark phase," highlighting their potential role in the sleep-wake cycle [45]. Further, administration of 2-AG in animals has been shown to augment slow wave sleep (SWS) and reduce paradoxical sleep (PS) when administered before the dark phase. However, when administered in the light phase, there may be less effect on SWS but higher impact on PS [46]. CB1 receptor antagonism in rodents after $4 \mathrm{~h}$ of light has also been shown to yield increased time spent in wakefulness and decreased time in SWS and REM sleep $[47,48]$.

In humans, it has been suggested that circadian rhythms are less pronounced after administration of THC. A study by Farabi et al. examined effects of dronabinol on quantitative sleep measures and found an increase in ultradian rhythms and changes in theta and delta frequencies, thus showing improved apneas and increased wakefulness [49].

The above studies identified a potential role of these compounds in various circadian rhythm disorders; further investigation is underway on utilizing them for therapeutic purposes.

\section{Endocannabinoids and Appetite}

The endocannabinoid system is involved in regulation of appetite, particularly the reward mechanism governing food intake and especially hedonic feeding (excessive food intake relative to the energy requirements) [50]. There is a suggestion that the endocannabinoid activity may be misaligned with central circadian rhythm especially in obese individuals highlighting its role in weight gain and reported preference of later timing of food intake [51]. A randomized crossover study comparing 4 nights of normal sleep $(8.5 \mathrm{~h}$ ) to sleep restriction $(4.5 \mathrm{~h})$ in healthy individuals showed amplified blood levels of endocannabinoids from mid-sleep to early afternoon when compared to normal sleep. These findings coincided with increased desire for palatable food suggesting a role of the endocannabinoid system in excessive food intake during sleep debt [52]. Moreover, a recent study further investigating the effect of sleep debt and the role of the endocannabinoid system found that there is enhanced encoding of food odors in the piriform cortex, which shifted food choices to more energy dense foods.

In summary, scientists may be able to develop a medication or lifestyle modification/behavioral therapy for conditions like obesity by understanding the role of the endocannabinoid 
system and its interaction with circadian rhythms and sleep restriction.

\section{Cannabinoids and Respiratory Center}

Inhalation of cannabis has variable effects on airways with acute versus chronic use. Acutely, it can lead to transient bronchodilation (due to its effect on local CB1 receptors in airway nerves) whereas chronic use has been shown to increase prevalence of chronic cough, wheezing, and increased incidence of acute bronchitis episodes in some studies [53]. In a population-based study, cannabis use has been shown to be associated with higher lung volumes and increased airway resistance in comparison with the tobacco group [54]. At clinical doses, these compounds lack any direct depressive effect on central respiratory centers unlike other psychoactive substances such as opiates [55].

It is well known that respiratory mechanics and ventilation are controlled by central and peripheral chemo-and mechanoreceptors. Vagal nerve innervated fibers are primarily present in these peripheral chemoreceptors. The afferent vagal nerves are present in nodose or inferior vagal ganglia which are connected to central receptors in the brainstem including nucleus ambiguous, dorsal vagal nucleus, and reticular formation [56] (Fig. 2). This nucleus serves as an important autonomic driver and is a primary site of action of multiple neurotransmitters including serotonin which regulates breathing patterns. During sleep, there are various autonomic changes including transient apneas, which are more frequent during REM. Serotonin receptors have been thought to regulate these apneas with stimulation yielding exacerbated apneas and blockade leading to decreased apneas [57]. Given the known effects of endocannabinoids on the serotonin receptors, it has been postulated that these compounds may also have a role in respiratory stabilization and management of sleep disordered breathing. In general, sleep apneas in an individual are usually a mix of both central and obstructive events. Any central neural motor output dysregulation is in part thought to be responsible for both processes. Anatomically, the upper airway is sometimes predisposed to collapse and with this dysregulated output, they primarily manifest as obstructive apneas. Rodents
Fig. 2 Vagal mediated responses on respiratory system

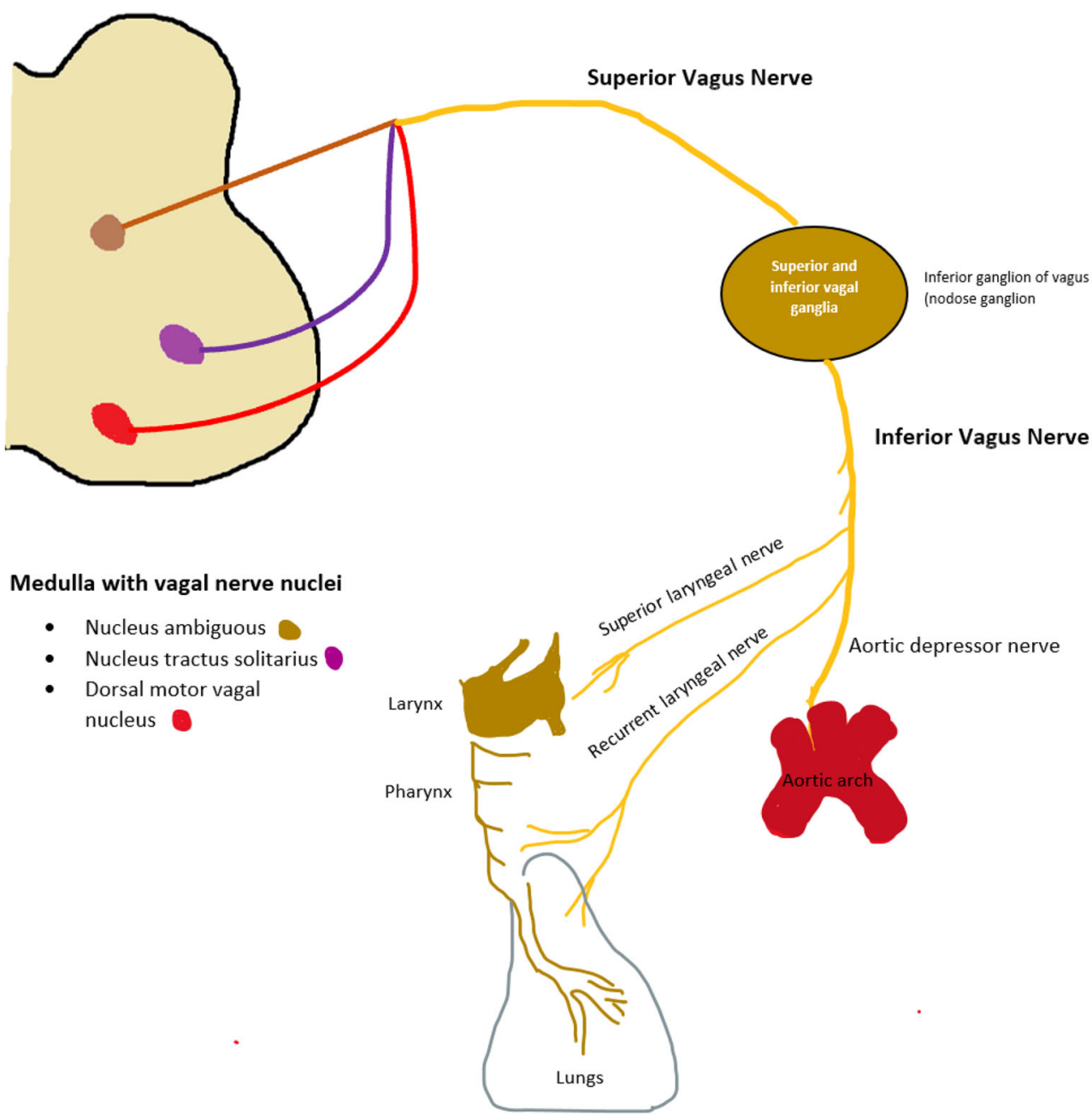


on the other hand have stable upper airway anatomy and dysregulation of the respiratory motor outputs leads to primarily central apneas. Furthermore, evidence of PAP therapy converting obstructive apneas to central apneas may support the role of dysregulated central motor pathways in the pathology of obstructive sleep apnea. Animal studies on Sprague rats by Carley et al. showed stabilization of respiratory patterns during sleep after injection of THC intraperitoneally, with dose-dependent effects on apneas. Though these rats primarily have central apneic events, it has been postulated that this could play a potential therapeutic role in humans for obstructive sleep apneas due to central respiratory motor patterns during sleep apnea and mixed apneas as mentioned above [57]. Small human studies have been performed demonstrating improvement in OSA severity with administration of dronabinol $[58,59]$.

The knowledge of the effects of cannabinoids on serotonin receptor-mediated respiratory regulation supports their potential role in sleep apneas (both central and obstructive).

\section{Therapeutic Role of Cannabinoids on Sleep Disorders}

\section{Insomnia}

Insomnia is a prevalent problem in the population with several recognized health consequences. Given limited therapeutic drug options and the potential deleterious health effects of available pharmacological agents, investigation of additional therapeutics is warranted. Due to their anxiolytic effect, cannabinoids have been historically used as sleeping aids [48]. Cannabinoids (CBD and THC) have variable effects on different sleep stages (as demonstrated by the hypnogram in Fig. 1). While some studies have demonstrated decreased insomnia severity with their use, most have shown mixed results. Applicability is also limited due to lack of assessment of doserelated effects.

CBD use has been shown to increase total sleep percentage with mid to high doses in rat models [40]. There is a dosedependent effect on REM sleep latency - with higher doses causing an increase in latency while mid-range doses yield a decrease [60]. Another study found that CBD had a positive effect on anxiety-related REM sleep suppression but no effect in the NREM phase. CBD used in combination with THC has been shown to decrease N3 sleep [28]. THC alone has been shown to decrease sleep latency but with long-term use it can decrease total sleep, likely due to tolerance of effect [61]. There is also increased evidence of improvement in insomnia symptoms secondary to chronic conditions. Patients with chronic conditions such as fibromyalgia frequently report insomnia. A study comparing the effect of synthetic THC (nabilone) versus amitriptyline on sleep in fibromyalgia patients with chronic insomnia demonstrated superiority of nabilone over amitriptyline in insomnia severity index and some improvement in restfulness [62]. It is unclear if this is due to the effect of marijuana on sleep quality or better pain control [63]. Recently, some randomized controlled trials (RCTs) are underway evaluating the effect of various cannabinoid products on chronic insomnia, which includes use of various combinations of CBD, THC, and cannabinol (CBN) or CBD alone [64-66]. One of these proposed trials, the CANSLEEP trial (cannabidiol and $\Delta^{9}$-tetrahydrocannabinol for chronic insomnia disorder), is a proof-of-concept trial evaluating safety and efficacy of single dose of ETC120 oil (a product containing THC and CBD) in chronic insomnia patients based on PSG data, EEG, and source modeling (using brain MRI) [67].

In summary, the effect of cannabinoids on sleep and insomnia is not only dose dependent, but also heavily influenced by type and combinations used. Before it can be reliably considered a choice for insomnia treatment, larger controlled studies are needed to better evaluate optimal doses as well as effects on various sleep stages.

\section{Restless Leg Syndrome}

Restless leg syndrome (RLS) is a sleep-related movement disorder accompanied by an unpleasant urge to move the legs, exacerbated by inactivity and relieved by movement, which can negatively affect sleep quality. This condition is often associated with a sleep-related movement disorder - periodic limb movement of sleep (PLMS) - which is diagnosed by PSG. RLS is thought to be related to several central neurotransmitters, chiefly including dopamine. Other associated neurotransmitters include glutamate, gamma-aminobutyric acid (GABA), and endogenous opioid [68-71]. Dopamine agonists have been a mainstay of treatment in addition to anticonvulsants and opiates. With the knowledge of the neuromodulatory effects of endocannabinoids (and the presence of associated receptors throughout pain pathways), there has been increased interest in use of cannabinoids for RLS. However, there has been limited evidence for their use to date. Two case series, one including 6 patients and another with 12 patients have shown near total remission in RLS with recreational marijuana smoking [72, 73]. Patients in both series continued previously prescribed medications for RLS while adding marijuana. PSG data are lacking on the effects of cannabinoids on sleep-related movement disorders. Further, in the absence of other robust clinical data, routine use cannot be recommended for RLS or PLMS at this time.

\section{Obstructive Sleep Apnea and Central Sleep Apnea}

Obstructive sleep apnea (OSA) is the most prevalent sleeprelated breathing disorder in the USA [74]. Central sleep 
apneas (CSAs) are caused by momentary failure of normal ventilatory rhythm during sleep. Both OSA and CSA may coexist in an individual. These conditions are primarily treated with positive airway pressure (PAP) therapy, the use of which is often limited due to non-adherence. This has led to investigation of other potential therapeutic alternatives. Multiple pharmacological agents have been investigated and found to have limited therapeutic potential. Recently, there has been increased interest in the use of cannabinoids primarily due to their neuromodulatory effect on the vagal nerve ganglion, as described above (and shown in Fig. 2). Albeit with small studies (and limited power), there have been some preliminarily promising results.

In animal studies, cannabinoids have been shown to reduce apneas (primarily serotonin induced) when injected intraperitoneally in Sprague-Dawley rats; however, they may yield decreased REM sleep and sleep efficiency [75, 76]. This has been further explored in other rat studies utilizing $\mathrm{CB}$ receptor antagonists and cannabinoids, which suggest a role of CB1 and $\mathrm{CB} 2$ receptors in suppressing apneas (as shown through dronabinol) [77]. Though anatomically rats exhibit central sleep apneas, these results can be interpreted in the context of OSA-related unstable respiratory patterns. In human studies, dronabinol has been shown to decrease Apnea-Hypopnea Index (AHI) and subjective sleepiness in a phase II placebocontrolled trial [58]. Though these preliminary human data are promising, larger follow-up studies including randomized control trials are needed to assess long-term efficacy and potential adverse effects.

\section{Post-Traumatic Stress Disorder-Related Nightmares}

Post-traumatic stress disorder (PTSD) is commonly associated with a range of sleep disturbances including insomnia, nightmares, and periodic limb movements [78]. Untreated sleep disturbances can further exacerbate PTSD symptoms. Its pathophysiology is linked to dysregulation of serotonin and noradrenaline as well as endogenous cannabinoids and opioids [79].

Nightmares can be difficult to treat and only few pharmacological medications are typically recommended, including prazosin as a first-line option [80]. With their known anxiolytic role, cannabinoids remain of interest and have been under investigation for PTSD. Cannabinoids could have a potential positive role due to their effect on the ECS and the limbic and paralimbic systems which decrease the activity of the amygdala and the hypothalamus yielding decreasing hypervigilance and hyperarousal [81].

Nabilone, a synthetic cannabinoid, has been studied for nightmares in PTSD patients. A study of 104 patients showed improvement in insomnia and nightmares [82]. Another study on treatment-resistant PTSD patients showed reduction in intensity of nightmares while improving sleep quality and time as well as decreasing flashbacks [83]. A small placebocontrolled trial also demonstrated reduction in nightmares [84].

An open-labeled study evaluated the role of THC in chronic PTSD, finding improvement in sleep quality and decreased nightmare frequency; however, some minor side effects were reported (e.g., dizziness, headache) [85]. Most studies have been limited by methodological heterogeneity as well as the use of variable dosages [86]. Furthermore, chronic cannabis use can be associated with habituation ultimately requiring increased usage for similar effects; abrupt withdrawal can yield relapse of symptoms [86]. More data are needed to support routine use for PTSD and nightmares.

A case series evaluating CBD for treatment of insomnia in patients with post-traumatic stress disorder (PTSD) showed decreased sleep disturbances per the Pittsburgh Sleep Quality Index (PSQI). A crossover study with nabilone that evaluated various polysomnography (PSG) parameters demonstrated increased sleep efficiency and total sleep time, as well as decreased arousal index; however, there was increased sleep onset latency [87].

\section{REM Behavior Disorder}

Rapid eye movement sleep behavior disorder (RBD) is a parasomnia caused by loss of atonia during REM sleep which leads to dream-enactment behaviors. This is commonly associated with various neurodegenerative disorders like multisystem atrophy, Lewy body dementia, and Parkinson's disease [88]. Pharmacological management of RBD is mainly limited to agents like benzodiazepines as well as melatonin; there is continued interest in exploration of other potential agents for treatment. A case series of patients with RBD, utilizing data from a placebo-controlled trial evaluating CBD's use in Parkinson's disease-related psychosis, found that four patients had reduction in frequency of RBD-related events without notable side effects $[89,90]$. To date, these represent the limited data available on evaluating the role of cannabinoids in RBD. With studies of limited sample size and lack of longterm outcomes, the role of cannabinoids in $\mathrm{RBD}$ remains largely undetermined.

\section{Narcolepsy}

Narcolepsy is a common cause of excessive daytime sleepiness and is associated with hypnagogic hallucinations, cataplexy, and sleep paralysis. This condition may be due to lack of orexin-A and B (also known as hypocretin) which are usually produced by the lateral hypothalamic neurons. These neurotransmitters play an active role in promoting wakefulness, as shown by animal models in which their depletion is associated with development of narcolepsy [91]. 
In contrast to the well-established role of THC in sleep promotion, CBD's effect is contradictory [92]. Some report improvement in sleep with CBD use, while others report increases in wakefulness $[28,93]$. This differential effect may be due to the heterogeneous methods used in the various studies evaluating the impact of CBD on sleep and wakefulness [94]. Recently, an animal study described the role of CBD in an orexin-deficient rat with narcolepsy which was injected with CBD at the beginning of the dark phase [95]. This resulted in blockade of excessive sleepiness during the lights-off period. The data regarding cannabinoid use in narcolepsy are largely pre-clinical. Human studies are needed to further evaluate their potential therapeutic role.

\section{Adverse Effects/Safety Considerations of Cannabinoids}

With the growing knowledge of the potential therapeutic benefits of cannabinoids, a better understanding of the associated adverse effects is needed. A meta-analysis, including 79 randomized control trials, summarized the benefits and adverse effects of their medical use. Commonly noted side effects included increased somnolence, dizziness, euphoria, disorientation, and paranoia.

In general, several short- and long-term adverse effects can occur with cannabinoid usage. Some short-term effects include impairment of memory and motor coordination, paranoia, and psychosis (with high doses). Other effects include dry mouth/throat, dry eyes, polyphagia, hyperemesis, inhalation-related burns, and risk of acute respiratory distress syndrome (ARDS) [96].

Long-term use has been associated with habituation, $\operatorname{cog}$ nitive impairment (especially in adolescents), exacerbation of mood and psychotic disorders, weight gain, and increased chronic bronchitis symptoms.

For sleep, short-term use has been shown to improve subjective and objective measures, but long-term effects are still unknown. Based on the limited available data on sleep disordered breathing, the American Academy of Sleep Medicine (AASM) has recommended against routine use of medical cannabis for OSA treatment [97].

\section{Impact of Legalization of Cannabinoids}

Even with legalization in multiple states in the USA, cannabis is still considered a drug of high abuse potential by the DEA. With limited scientific data to question its safety and increased publicity for medicinal use, there is a reduced risk perception among the public. This is especially worrisome for vulnerable populations like adolescents and children. Long-term safety data are lacking, further limiting the establishment of a safety profile. Use in younger ages has been shown to cause restless and irregular sleep. This population also has a higher potential for dependence and has been shown to have higher rates of mental impairment in adulthood [98].

\section{Conclusion}

The recent trend for legalization of medicinal cannabis and cannabinoid-containing products, together with their soporific effects, has led to a surge of interest of their potential therapeutic role in the management of some common sleep disorders, such as insomnia, sleep disordered breathing, and restless legs syndrome, and less common disorders such as narcolepsy and parasomnias. However, the science of cannabinoids in various sleep disorders is still in infancy. Our review summarizes the mechanism, role, and current body of literature on cannabinoids in various sleep disorders. Though widely utilized historically and legally in many parts of the world, robust knowledge about the effects of these substances, especially long term, is lacking. Most studies are pre-clinical or have small sample sizes which limit their applicability. Currently, some placebo-controlled trials are underway for evaluation of the effects on sleep apnea and insomnia [99].

Overall, synthetic derivatives in their purest form with known mechanism of action, route of administration, and thoroughly studied pharmacology have a greater potential of revolutionizing their therapeutic role in sleep disorders.

Supplementary Information The online version contains supplementary material available at https://doi.org/10.1007/s13311-021-01013-w.

\section{References}

1. Pertwee R. ed. Handbook of Cannabis. Oxford University Press; 2014. Available at: https://www.oxfordscholarship.eom/view/10. 1093 /acprof:oso/9780199662685.001.0001/acprof9780199662685. Published online January 2015. Accessed 22 Dec 2020.

2. Mead A. Legal and Regulatory Issues Governing Cannabis and Cannabis-Derived Products in the United States. Front Plant Sci 2019;10:697.

3. Most Commonly Used Addictive Drugs. National Institute on Drug Abuse website. June 25,2020 [online]. Available from: https://www.drugabuse.gov/publications/media-guide/mostcommonly-used-addictivedrugs. Accessed 28 Dec 2020.

4. Zias J, Stark H, Sellgman J, Levy R, Werker E, Breuer A, et al. Early medical use of cannabis. Nature. 1993;363(6426):215.

5. Abuhasira R, Shbiro L, Landschaft Y. Medical use of cannabis and cannabinoids containing products - Regulations in Europe and North America. Eur J Intern Med 2018;49:2-6.

6. NCSL (Natl. Conf. State Legis.). State medical marijuana laws, June 27,2018 [online] Available from: https://www.ncsl.org/ 
research/health/state-medical-marijuana-laws.aspx. Accessed 28 Dec 2020.

7. Allan GM, Finley CR, Ton J, Perry D, Ramji J, Crawford K, et al. Systematic review of systematic reviews for medical cannabinoids: Pain, nausea and vomiting, spasticity, and harms. Can Fam Physician 2018;64(2):e78-e94.

8. España RA, Scammell TE. Sleep neurobiology from a clinical perspective. Sleep. 2011;34(7):845-58.

9. España RA, Scammell TE. Sleep neurobiology for the clinician. Sleep. 2004;27(4):811-20.

10. Steriade M, Datta S, Paré D, Oakson G, Curró Dossi RC. Neuronal activities in brain-stem cholinergic nuclei related to tonic activation processes in thalamocortical systems. J Neurosci 1990;10(8):2541-59.

11. In: Colten HR, Altevogt BM, editors. Sleep Disorders and Sleep Deprivation: An Unmet Public Health Problem. The National Academies Collection: Reports funded by National Institutes of Health. Washington (DC)2006.

12. Henke KG, Badr MS, Skatrud JB, Dempsey JA. Load compensation and respiratory muscle function during sleep. J Appl Physiol (1985). 1992;72(4):1221-34.

13. Greenberg HE, Scharf SM. Depressed ventilatory load compensation in sleep apnea. Reversal by nasal CPAP. Am Rev Respir Dis 1993;148(6 Pt 1):1610-5.

14. Pertwee RG. The pharmacology of cannabinoid receptors and their ligands: an overview. Int J Obes 2006;30 Suppl 1:S13-8.

15. Glass M, Dragunow M, Faull RL. Cannabinoid receptors in the human brain: a detailed anatomical and quantitative autoradiographic study in the fetal, neonatal and adult human brain. Neuroscience. 1997;77(2):299-318

16. Munro S, Thomas KL, Abu-Shaar M. Molecular characterization of a peripheral receptor for cannabinoids. Nature. 1993;365(6441):61-5.

17. Brown SM, Wager-Miller J, Mackie K. Cloning and molecular characterization of the rat $\mathrm{CB} 2$ cannabinoid receptor. Biochim Biophys Acta 2002;1576(3):255-64.

18. Van Sickle MD, Duncan M, Kingsley PJ, Mouihate A, Urbani P, Mackie $\mathrm{K}$, et al. Identification and functional characterization of brainstem cannabinoid CB2 receptors. Science. 2005;310(5746): 329-32.

19. Murillo-Rodríguez E. The role of the CB1 receptor in the regulation of sleep. Prog Neuro-Psychopharmacol Biol Psychiatry 2008;32(6):1420-7.

20. Maejima T, Masseck OA, Mark MD, Herlitze S. Modulation of firing and synaptic transmission of serotonergic neurons by intrinsic $\mathrm{G}$ protein-coupled receptors and ion channels. Front Integr Neurosci. 2013;7:40-.

21. Brown RE, Sergeeva OA, Eriksson KS, Haas HL. Convergent excitation of dorsal raphe serotonin neurons by multiple arousal systems (orexin/hypocretin, histamine and noradrenaline). J Neurosci 2002;22(20):8850-9.

22. Devlin MG, Christopoulos A. Modulation of cannabinoid agonist binding by $5-\mathrm{HT}$ in the rat cerebellum. J Neurochem 2002;80(6): 1095-102.

23. Fan P. Cannabinoid agonists inhibit the activation of 5-HT3 receptors in rat nodose ganglion neurons. J Neurophysiol 1995;73(2):907-10.

24. Haj-Dahmane S, Shen R-Y. Modulation of the serotonin system by endocannabinoid signaling. Neuropharmacology. 2011;61(3): 414-20.

25. Haj-Dahmane S, Shen RY. The wake-promoting peptide orexin-B inhibits glutamatergic transmission to dorsal raphe nucleus serotonin neurons through retrograde endocannabinoid signaling. $\mathrm{J}$ Neurosci 2005;25(4):896-905.
26. Babson KA, Sottile J, Morabito D. Cannabis, Cannabinoids, and Sleep: a Review of the Literature. Curr Psychiatry Rep 2017;19(4):23.

27. Babson K, Bonn-Miller M. Sleep Disturbances: Implications for Cannabis Use, Cannabis Use Cessation, and Cannabis Use Treatment. Curr Addict Rep 2014;1:109-14.

28. Nicholson AN, Turner C, Stone BM, Robson PJ. Effect of Delta9-tetrahydrocannabinol and cannabidiol on nocturnal sleep and early-morning behavior in young adults. J Clin Psychopharmacol 2004;24(3):305-13.

29. Pivik RT, Zarcone V, Dement WC, Hollister LE. Delta-9tetrahydrocannabinol and synhexl: effects on human sleep patterns. Clin Pharmacol Ther 1972;13(3):426-35.

30. Fujimori M, Himwich HE. $\Delta 9$-Tetrahydrocannabinol and the sleep-wakefulness cycle in rabbits. Physiol Behav 1973;11(3): 291-5.

31. Wallach MB, Gershon S. The effects of delta8-THC on the EEG, reticular multiple unit activity and sleep of cats. Eur J Pharmacol 1973;24(2):172-8.

32. Barratt ES, Adams PM. Chronic marijuana usage and sleepwakefulness cycles in cats. Biol Psychiatry 1973;6(3):207-14.

33. Pranikoff K, Karacan I, Larson EA, Williams RL, Thornby JI, Hursch CJ. Effects of marijuana smoking on the sleep EEG. Preliminary studies. Jfma. 1973;60(3):28-31.

34. Adams PM, Barratt ES. Effect of chronic marijuana administration of stages of primate sleep-wakefulness. Biol Psychiatry 1975;10(3):315-22.

35. Pacek LR, Herrmann ES, Smith MT, Vandrey R. Sleep continuity, architecture and quality among treatment-seeking cannabis users: An in-home, unattended polysomnographic study. Exp Clin Psychopharmacol 2017;25(4):295-302.

36. Bolla KI, Brown K, Eldreth D, Tate K, Cadet JL. Dose-related neurocognitive effects of marijuana use. Neurology. 2002;59(9): 1337-43.

37. Budney AJ, Moore BA, Vandrey RG, Hughes JR. The time course and significance of cannabis withdrawal. J Abnorm Psychol 2003;112(3):393-402.

38. Bolla KI, Lesage SR, Gamaldo CE, Neubauer DN, Wang NY, Funderburk FR, et al. Polysomnogram changes in marijuana users who report sleep disturbances during prior abstinence. Sleep Med 2010;11(9):882-9.

39. Hser YI, Mooney LJ, Huang D, Zhu Y, Tomko RL, McClure E, et al. Reductions in cannabis use are associated with improvements in anxiety, depression, and sleep quality, but not quality of life. J Subst Abus Treat 2017;81:53-8.

40. Chagas MH, Crippa JA, Zuardi AW, Hallak JE, Machado-deSousa JP, Hirotsu C, et al. Effects of acute systemic administration of cannabidiol on sleep-wake cycle in rats. J Psychopharmacol 2013;27(3):312-6.

41. Monti JM. Hypnoticlike effects of cannabidiol in the rat Psychopharmacology 1977;55(3):263-5.

42. Spindle TR, Cone EJ, Goffi E, Weerts EM, Mitchell JM, Winecker RE, et al. Pharmacodynamic effects of vaporized and oral cannabidiol (CBD) and vaporized CBD-dominant cannabis in infrequent cannabis users. Drug Alcohol Depend 2020;211: 107937.

43. Sanford AE, Castillo E, Gannon RL. Cannabinoids and hamster circadian activity rhythms. Brain Res 2008;1222:141-8.

44. Acuna-Goycolea C, Obrietan K, van den Pol AN. Cannabinoids excite circadian clock neurons. J Neurosci 2010;30(30):10061-6.

45. Murillo-Rodriguez E, Palomero-Rivero M, Millan-Aldaco D, Mechoulam R, Drucker-Colin R. Effects on sleep and dopamine levels of microdialysis perfusion of cannabidiol into the lateral hypothalamus of rats. Life Sci 2011;88(11-12):504-11. 
46. Pava MJ, Makriyannis A, Lovinger DM. Endocannabinoid Signaling Regulates Sleep Stability. PLoS One 2016;11(3): e0152473.

47. Vaughn LK, Denning G, Stuhr KL, de Wit H, Hill MN, Hillard CJ. Endocannabinoid signalling: has it got rhythm? Br J Pharmacol 2010;160(3):530-43.

48. Kesner AJ, Lovinger DM. Cannabinoids, Endocannabinoids and Sleep, Front Mol Neurosci 2020;13:125.

49. Farabi SS, Prasad B, Quinn L, Carley DW. Impact of dronabinol on quantitative electroencephalogram (qEEG) measures of sleep in obstructive sleep apnea syndrome. J Clin Sleep Med 2014;10(1):49-56.

50. Coccurello R, Maccarrone M. Hedonic Eating and the "Delicious Circle": From Lipid-Derived Mediators to Brain Dopamine and Back. Front Neurosci. 2018;12:271-.

51. Hanlon EC, Leproult R, Stuhr KL, Doncheck EM, Hillard CJ, Van Cauter E. Circadian Misalignment of the 24-hour Profile of Endocannabinoid 2-Arachidonoylglycerol (2-AG) in Obese Adults. J Clin Endocrinol Metab 2020;105(3):792-802.

52. Hanlon EC, Tasali E, Leproult R, Stuhr KL, Doncheck E, de Wit $\mathrm{H}$, et al. Sleep Restriction Enhances the Daily Rhythm of Circulating Levels of Endocannabinoid 2-Arachidonoylglycerol. Sleep. 2016;39(3):653-64.

53. Tashkin DP. Effects of marijuana smoking on the lung. Ann Am Thorac Soc 2013;10(3):239-47.

54. Hancox RJ, Poulton R, Ely M, Welch D, Taylor DR, McLachlan $\mathrm{CR}$, et al. Effects of cannabis on lung function: a population-based cohort study. Eur Respir J 2010;35(1):42-7.

55. Vachon L, FitzGerald MX, Solliday NH, Gould IA, Gaensler EA. Single-dose effects of marihuana smoke. Bronchial dynamics and respiratory-center sensitivity in normal subjects. N Engl J Med 1973;288(19):985-9.

56. Kaczynska K, Szereda-Przestaszewska M. Nodose gangliamodulatory effects on respiration. Physiol Res 2013;62(3):22735.

57. Carley DW, Prasad B, Reid KJ, Malkani R, Attarian H, Abbott SM, et al. Pharmacotherapy of Apnea by Cannabimimetic Enhancement, the PACE Clinical Trial: Effects of Dronabinol in Obstructive Sleep Apnea. Sleep 2018, 41, https://doi.org/10.1093/ sleep/zsx184.

58. Carley DW, Prasad B, Reid KJ, Malkani R, Attarian H, Abbott SM, et al. Pharmacotherapy of Apnea by Cannabimimetic Enhancement, the PACE Clinical Trial: Effects of Dronabinol in Obstructive Sleep Apnea. Sleep. 2018;41(1).

59. Prasad B, Radulovacki MG, Carley DW. Proof of concept trial of dronabinol in obstructive sleep apnea. Front Psychiatry 2013;4:1.

60. Hsiao YT, Yi PL, Li CL, Chang FC. Effect of cannabidiol on sleep disruption induced by the repeated combination tests consisting of open field and elevated plus-maze in rats. Neuropharmacology. 2012;62(1):373-84.

61. Gorelick DA, Goodwin RS, Schwilke E, Schwope DM, Darwin WD, Kelly DL, et al. Tolerance to effects of high-dose oral delta9tetrahydrocannabinol and plasma cannabinoid concentrations in male daily cannabis smokers. J Anal Toxicol 2013;37(1):11-6.

62. Ware MA, Fitzcharles MA, Joseph L, Shir Y. The effects of nabilone on sleep in fibromyalgia: results of a randomized controlled trial. Anesth Analg 2010;110(2):604-10.

63. Russo EB, Guy GW, Robson PJ. Cannabis, pain, and sleep: lessons from therapeutic clinical trials of Sativex, a cannabis-based medicine. Chem Biodivers 2007;4(8):1729-43.

64. Ware M. Investigation of the efficacy and safety of CHI-921 insomnia. 2019 June 13 [last updated 2020 October 5]. In ClinicalTrials.gov [Internet]. Montréal, Quebec, Canada. Available from: https://clinicaltrials.gov/ct2/show/ NCT03984604? cond=Investigation+of+the+Efficacy+and+ Safety+of+CHI-921+in+Insomnia. \&draw $=2 \&$ rank $=1$.
ClinicalTrials.gov Identifier: NCT03984604. Access date 11 Sep 2020.

65. Eastwood P. A trial to evaluate an oral medicinal cannabis extract compared with placebo for the treatment of insomnia. 2017 December 1 [last updated 2020 March 12]. In ANZCTR.org.au [Internet] Available from: https://www.anzctr.org.au/Trial/ Registration/TrialReview.aspx $\mathrm{id}=373959 \&$ showHistory= true \& is Review $=$ true. Registration number: ACTRN12618000078257. Accessed 22 Oct 2020

66. Hayley A. Cannabidiol (CBD) treatment for insomnia: a threeweek randomised controlled pilot trial with a placebo run-in period (CBD-INS). 2020 January 7 [ last updated 2020 March 20]. In ANZCTR.org.au [Internet] Available from: https://www.anzctr. org.au/Trial/Registration/TrialReview.aspx?id= 379003 \& is Review $=$ true. Registration number: ACTRN12620000070932. Access date October 22, 2020

67. Suraev A, Grunstein RR, Marshall NS, D'Rozario AL, Gordon CJ, Bartlett DJ, et al. Cannabidiol (CBD) and Delta(9)-tetrahydrocannabinol (THC) for chronic insomnia disorder ('CANSLEEP' trial): protocol for a randomised, placebo-controlled, double-blinded, proof-of-concept trial. BMJ Open 2020;10(5):e034421.

68. Červenka S, Pålhagen SE, Comley RA, Panagiotidis G, Cselényi Z, Matthews JC, et al. Support for dopaminergic hypoactivity in restless legs syndrome: a PET study on D2-receptor binding. Brain. 2006;129(8):2017-28.

69. Allen RP, Barker PB, Horska A, Earley CJ. Thalamic glutamate/ glutamine in restless legs syndrome: increased and related to disturbed sleep. Neurology. 2013;80(22):2028-34.

70. Winkelman JW, Schoerning L, Platt S, Jensen JE. Restless legs syndrome and central nervous system gamma-aminobutyric acid: preliminary associations with periodic limb movements in sleep and restless leg syndrome symptom severity. Sleep Med 2014;15(10):1225-30.

71. von Spiczak S, Whone AL, Hammers A, Asselin MC, Turkheimer $\mathrm{F}$, Tings $\mathrm{T}$, et al. The role of opioids in restless legs syndrome: an [11C]diprenorphine PET study. Brain. 2005;128(Pt 4):906-17.

72. Megelin T, Ghorayeb I. Cannabis for restless legs syndrome: a report of six patients. Sleep Med 2017;36:182-3.

73. Ghorayeb I. More evidence of cannabis efficacy in restless legs syndrome. Sleep Breath 2020;24(1):277-9.

74. Malhotra A, Ayas N, Patel SR, Peppard PE, Tufik S, Valentine K, et al. 0477 Americas Prevalence of OSA in Adults: Estimation Using Currently Available Data. Sleep. 2019;42:A191.

75. Calik MW, Radulovacki M, Carley DW. Intranodose ganglion injections of dronabinol attenuate serotonin-induced apnea in Sprague-Dawley rat. Respir Physiol Neurobiol 2014;190:20-4.

76. Calik MW, Carley DW. Effects of Cannabinoid Agonists and Antagonists on Sleep and Breathing in Sprague-Dawley Rats. Sleep. 2017;40(9).

77. Calik MW, Radulovacki M, Carley DW. A method of nodose ganglia injection in Sprague-Dawley rat. J Vis Exp 2014(93): e52233.

78. Koffel E, Khawaja IS, Germain A. Sleep Disturbances in Posttraumatic Stress Disorder: Updated Review and Implications for Treatment. Psychiatr Ann 2016;46(3):173-6.

79. Bailey CR, Cordell E, Sobin SM, Neumeister A. Recent progress in understanding the pathophysiology of post-traumatic stress disorder: implications for targeted pharmacological treatment. CNS Drugs 2013;27(3):221-32.

80. Aurora RN, Zak RS, Auerbach SH, Casey KR, Chowdhuri S, Karippot A, et al. Best practice guide for the treatment of nightmare disorder in adults. J Clin Sleep Med 2010;6(4):389-401.

81. Bitencourt RM, Takahashi RN. Cannabidiol as a Therapeutic Alternative for Post-traumatic Stress Disorder: From Bench Research to Confirmation in Human Trials. Front Neurosci 2018;12:502. 
82. Cameron C, Watson D, Robinson J. Use of a synthetic cannabinoid in a correctional population for posttraumatic stress disorderrelated insomnia and nightmares, chronic pain, harm reduction, and other indications: a retrospective evaluation. J Clin Psychopharmacol 2014;34(5):559-64.

83. Fraser GA. The use of a synthetic cannabinoid in the management of treatment-resistant nightmares in posttraumatic stress disorder (PTSD). CNS Neurosci Ther 2009;15(1):84-8.

84. Jetly R, Heber A, Fraser G, Boisvert D. The efficacy of nabilone, a synthetic cannabinoid, in the treatment of PTSD-associated nightmares: A preliminary randomized, double-blind, placebocontrolled cross-over design study. Psychoneuroendocrinology. 2015;51:585-8.

85. Roitman P, Mechoulam R, Cooper-Kazaz R, Shalev A. Preliminary, open-label, pilot study of add-on oral $\Delta$ 9-tetrahydrocannabinol in chronic post-traumatic stress disorder. Clin Drug Investig 2014;34(8):587-91.

86. Orsolini L, Chiappini S, Volpe U, Berardis D, Latini R, Papanti GD, Corkery AJM. Use of Medicinal Cannabis and Synthetic Cannabinoids in Post-Traumatic Stress Disorder (PTSD): A Systematic Review. Medicina (Kaunas). 2019 Aug 23;55(9):525.

87. Zalai D, Chung S, Hussain N, Shapiro C. Does cannabinoid really improve sleep? Testing the sleep effects of nabilone in chronic pain patients: a placebo-controlled, randomized, pilot study. Psychotherapy and Psychosomatics. 2015;84. Available at www. semanticscholar.org. Accessed 19 Dec 2020.

88. Jiang H, Huang J, Shen Y, Guo S, Wang L, Han C, et al. RBD and Neurodegenerative Diseases. Mol Neurobiol 2017;54(4):29973006.

89. Chagas MH, Eckeli AL, Zuardi AW, Pena-Pereira MA, SobreiraNeto MA, Sobreira ET, et al. Cannabidiol can improve complex sleep-related behaviours associated with rapid eye movement sleep behaviour disorder in Parkinson's disease patients: a case series. J Clin Pharm Ther 2014;39(5):564-6.

90. Zuardi AW, Crippa JA, Hallak JE, Pinto JP, Chagas MH, Rodrigues GG, et al. Cannabidiol for the treatment of psychosis in Parkinson's disease. J Psychopharmacol 2009;23(8):979-83.

91. Chemelli RM, Willie JT, Sinton CM, Elmquist JK, Scammell T, Lee C, et al. Narcolepsy in orexin knockout mice: molecular genetics of sleep regulation. Cell. 1999;98(4):437-51.
92. Feinberg I, Jones R, Walker JM, Cavness C, March J. Effects of high dosage delta-9-tetrahydrocannabinol on sleep patterns in man. Clin Pharmacol Ther 1975;17(4):458-66.

93. Carlini EA, Cunha JM. Hypnotic and antiepileptic effects of cannabidiol. J Clin Pharmacol. 1981;21(S1):417s-27s.

94. Murillo-Rodríguez E, Sarro-Ramírez A, Sánchez D, MijangosMoreno S, Tejeda-Padrón A, Poot-Aké A, et al. Potential effects of cannabidiol as a wake-promoting agent. Curr Neuropharmacol 2014;12(3):269-72.

95. Murillo-Rodriguez E, Millan-Aldaco D, Palomero-Rivero M, Morales-Lara D, Mechoulam R, Drucker-Colin R. Cannabidiol Partially Blocks the Excessive Sleepiness in Hypocretindeficient Rats: Preliminary Data. CNS Neurol Disord Drug Targets 2019;18(9):705-12.

96. Volkow ND, Baler RD, Compton WM, Weiss SR. Adverse health effects of marijuana use. N Engl J Med 2014;370(23):2219-27.

97. Ramar K, Rosen IM, Kirsch DB, Chervin RD, Carden KA, Aurora RN, et al. Medical Cannabis and the Treatment of Obstructive Sleep Apnea: An American Academy of Sleep Medicine Position Statement. J Clin Sleep Med 2018;14(04):679-81.

98. Hasler BP, Kirisci L, Clark DB. Restless Sleep and Variable Sleep Timing During Late Childhood Accelerate the Onset of Alcohol and Other Drug Involvement. J Stud Alcohol Drugs 2016;77(4): 649-55.

99. Suraev AS, Marshall NS, Vandrey R, McCartney D, Benson MJ, McGregor IS, et al. Cannabinoid therapies in the management of sleep disorders: A systematic review of preclinical and clinical studies. Sleep Med Rev 2020;53:101339.

100. Goril S, Shapiro C. The Patterns of Sleep Disorders and Circadian Rhythm Disruptions in Children and Adolescents with Fetal Alcohol Spectrum Disorders. 2011. In: ResearchGate [online]. Available from: https://www.researchgate.net/profile/Colin Shapiro/publication/267910844/figure/download/fig1/AS: 655137936773120@1533208464033/Hypnogram-of-sleepcycle-in-a-healthy-young-adult-Normal-sleep-involvescycling. png. Accessed 17 Nov 2020.

Publisher's Note Springer Nature remains neutral with regard to jurisdictional claims in published maps and institutional affiliations. 